\title{
Correlation of Burning Rate of the Interacting Liquid Droplets with Internal Circulation*
}

\author{
Ho Young $\mathrm{KIM}^{* *}$, Chong Pyo $\mathrm{CHO}^{* * *}$ and Jin Taek $\mathrm{CHUNG}^{* *}$
}

\begin{abstract}
The combustion characteristics of interacting liquid droplets with internal circulation in a convective flow are numerically investigated in order to determine the burning rate correlation of interacting droplets. For the transient analysis of 2-dimensionally arranged interacting droplets, Reynolds number based on the relative velocity between the liquid droplet and surrounding gas, vertical and horizontal distances between neighboring droplets are chosen as major parameters. The time variations of flame structure and combustion characteristics as well as the burning rate during the droplet lifetime are obtained. The results reveal that the transient flame configuration and retardation of droplet internal motion for the arbitrary droplets arrangement substantially influence on the burning rate of interacting droplets. The burning rate of interacting droplets exhibits a strong dependence on Reynolds number, the horizontal and vertical distances between droplets. The correction factor of burning rate for interacting droplets based on the single droplet combustion is also suggested in terms of major parameters.
\end{abstract}

Key Words: Liquid Fuel, Forced Convection, Interacting Droplet, Burning Rate, Horizontal Distance, Vertical Distance, Correction Factor

\section{Introduction}

In spray combustion, different modes of the liquid fuel burning take place including external group combustion, in which a diffusion flame surrounds all vaporizing droplets inside the spray core, and internal group combustion, in which the primary flame is located inside the spray boundary, and some droplets may burn individually or as a group, on the oxidizer side of the primary flame ${ }^{(1)}$. The results obtained from single droplet combustion can be used as the fundamental information for the spray calculation. The burning behavior of interacting droplets, however, is quite different from that of the single droplet. To investigate basic mechanism of spray combustion, the combustion of two droplets and droplet arrays has been studied experimentally ${ }^{(2)-(4)}$ and theoretically ${ }^{(5),(6)}$. In practical combustion process, the interaction between atomized droplet and surrounding gas flow affects droplet vaporization rate and flame configuration

* Received 11th November, 2004 (No. 04-5178)

** Department of Mechanical Engineering, Korea University, 5-ka Anam-dong, Sungbuk-ku, Seoul 136-713, Korea. E-mail: kimhy@korea.ac.kr

*** Department of Mechanical Engineering, Korea University, 5-ka Anam-dong, Sungbuk-ku, Seoul 136-713, Korea which are quite different from those in a stagnant environment. In a convective flow, liquid-phase internal circulation inside droplet significantly affects the droplet heating process $^{(7)}$. In an oxidizing-convective flow, additionally, four different flame modes of droplet are possible: an envelope flame, a transition flame, a wake flame and pure vaporization mode as predicted by Dwyer and Sanders ${ }^{(8)}$ for a vaporizing droplet, and by Jiang et al. ${ }^{(9)}$ for a convective $n$-octane droplet burning in air. According to their studies, flame configuration varies from wake flame mode to envelope flame mode with decreasing Reynolds number and increasing Damköhler number. As stated above, the vaporization and combustion processes of a cloud of droplets interacting with a gaseous environment and with each other are very complex. For multiple droplet systems, few investigations concerning unsteady droplet combustion have been done. The study on the burning of droplet arrays is effective to improve basic understanding of spray combustion. The objective of present work is to examine the burning behavior of linearly arranged droplets with combustion in convective environments. Results will not only enhance basic understanding of the burning behavior of droplets, but will be used to establish relevant correlations for the burning rate of interacting droplet to that of single droplet burning in terms of droplet spacing and Reynolds 
number suitable for applications in spray modeling.

\section{Formulation}

Figure 1 shows the physical configuration of present calculation where droplets are linearly arranged in convective flow. The fuel droplets are assumed to vaporize in a micro-gravity environment and natural convection effects are thus not considered. Effects of thermal radiation and droplet deformation are neglected since at a low pressure those are of secondary importance. Surface force due to the temperature- dependent nature of the surface tension is also neglected. The governing equations for both phases are given as follow:

Gas phase

$$
\begin{aligned}
& \frac{\partial \rho}{\partial t}+\frac{\partial}{\partial x_{i}}\left\{\rho\left(u_{i}-\frac{\partial x_{i}}{\partial t}\right)\right\}=0 \\
& \frac{\partial}{\partial t}\left(\rho u_{i}\right)+\frac{\partial}{\partial x_{j}}\left\{\rho\left(u_{i}-\frac{\partial x_{i}}{\partial t}\right) u_{j}\right\} \\
& =-\frac{\partial P}{\partial x_{i}}+\frac{\partial}{\partial x_{j}}\left\{\mu\left(\frac{\partial u_{i}}{\partial x_{j}}+\frac{\partial u_{j}}{\partial x_{i}}\right)\right\}-\frac{2}{3} \frac{\partial}{\partial x_{i}}\left(\frac{\partial u_{j}}{\partial x_{j}}\right) \\
& \frac{\partial}{\partial t}(\rho h)+\frac{\partial}{\partial x_{j}}\left\{\rho\left(u_{j}-\frac{\partial x_{j}}{\partial t}\right) h\right\} \\
& =\frac{\partial}{\partial x_{j}}\left(\frac{k}{c_{p}} \frac{\partial h}{\partial x_{j}}\right)+\sum_{n=1}^{N} \Delta h_{n} \dot{w}_{n} \\
& \frac{\partial}{\partial t}\left(\rho Y_{k}\right)+\frac{\partial}{\partial x_{j}}\left\{\rho\left(u_{j}-\frac{\partial x_{j}}{\partial t}\right) Y_{k}\right\} \\
& =\frac{\partial}{\partial x_{j}}\left(\rho D_{k} \frac{\partial Y_{k}}{\partial x_{j}}\right)+\sum_{n=1}^{N} v_{k n} \dot{w}_{n}
\end{aligned}
$$

The equation of state created by Peng-Robinson ${ }^{(10)}$ is used. Here, a single-step global finite-rate chemical reaction is assumed for the combustion of $n$-heptane. The stoichiometric reaction equation for the oxidation of $n$ heptane is written as:

$$
\mathrm{C}_{7} \mathrm{H}_{16}+11\left(\mathrm{O}_{2}+3.76 \mathrm{~N}_{2}\right) \rightarrow 7 \mathrm{CO}_{2}+8 \mathrm{H}_{2} \mathrm{O}+41.36 \mathrm{~N}_{2}
$$

The reaction rate, as suggested by Westbrook et al. ${ }^{(11)}$, is given as follows:

$$
\dot{\omega}=5.1 \times 10^{11} \exp (-30 / R T)\left[\mathrm{C}_{7} \mathrm{H}_{16}\right]^{1 / 4}\left[\mathrm{O}_{2}\right]^{3 / 2}
$$

Governing equations for the orthogonal coordinate have been transformed into a general curvilinear coordinates $(\xi, \eta)$. The calculation can be performed on a rectangular mesh with equal spacing $(\Delta \xi=\Delta \eta=1)$.

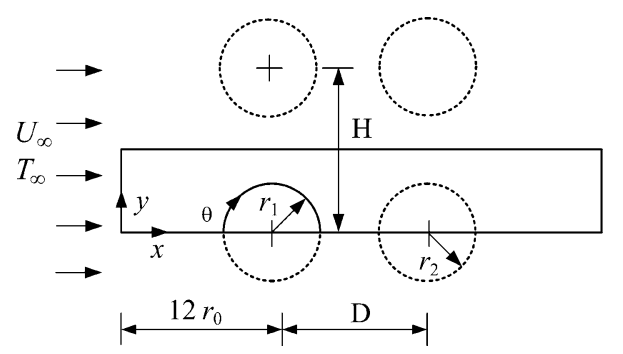

Fig. 1 Schematic of fuel droplets burning in a convective flow
Liquid phase

$$
\begin{aligned}
& \frac{\partial \rho}{\partial t}+\frac{\partial}{\partial x_{i}}\left\{\rho\left(u_{i}-\frac{\partial x_{i}}{\partial t}\right)\right\}=0 \\
& \frac{\partial}{\partial t}\left(\rho u_{i}\right)+\frac{\partial}{\partial x_{j}}\left\{\rho\left(u_{i}-\frac{\partial x_{i}}{\partial t}\right) u_{j}\right\} \\
& \quad=-\frac{\partial P}{\partial x_{i}}+\frac{\partial}{\partial x_{j}}\left\{\mu\left(\frac{\partial u_{i}}{\partial x_{j}}+\frac{\partial u_{j}}{\partial x_{i}}\right)\right\}-\frac{2}{3} \frac{\partial}{\partial x_{i}}\left(\frac{\partial u_{j}}{\partial x_{j}}\right) \\
& \frac{\partial}{\partial t}\left(\rho c_{p} T\right)+\frac{\partial}{\partial x_{j}}\left\{\rho c_{p}\left(u_{j}-\frac{\partial x_{j}}{\partial t}\right) T\right\}=\frac{\partial}{\partial x_{j}}\left(k \frac{\partial T}{\partial x_{j}}\right)
\end{aligned}
$$

Initial conditions

$$
u_{g}=u_{\infty}, T_{g}=T_{\infty}, \quad Y_{o}=Y_{o, \infty}, \quad Y_{f}=Y_{f, \infty}, T_{l}=T_{o}
$$

Boundary conditions

a ) At the droplet center $(r=0)$

$$
v_{l}=\frac{\partial \phi}{\partial n}=0 \quad \text { where } \quad \phi=u_{l}, T_{l}, Y_{f}
$$

b ) At the droplet surface $(r=r(t))$

$$
\begin{aligned}
& u_{l, s}=u_{g, s}, \quad \tau_{l, s}=\tau_{g, s}, \quad T_{l, s}=T_{g, s} \\
& \dot{m}^{\prime \prime}=Y_{f} \dot{m}^{\prime \prime}-\rho_{g} D_{g}\left(\frac{d Y_{f}}{d n}\right)_{s} \\
& \left(k \frac{\partial T}{\partial n}\right)_{g, s}=\left(k \frac{\partial T}{\partial n}\right)_{l, s}+\dot{m}^{\prime \prime} L
\end{aligned}
$$

Fuel vapor concentration at the surface can be obtained by use of the Wagner equation given by Ambrose et al. ${ }^{(10)}$ :

$$
\left(\chi_{f}\right)_{s} p_{r e f}=p_{c} \exp \left[\left(a \tau+b \tau^{1.5}+c \tau^{2.5}+d \tau^{5}\right) / T_{r}\right]
$$

where $\tau=1-\left(T_{s} / T_{c}\right), a=-7.77404, b=1.85614, c=$ $-2.8298, d=-3.507$.

Because of symmetry, all gradients at the centerline $(y=0)$ and upper domain boundary are equal to zero.

The methods to evaluate the thermophysical properties are summarized in Table 1. In the interface of droplets, mass flux is calculated by diffusion theory including the effects of diffusion-induced convection and the effects of the moving interface ${ }^{(12)}$ instead of classical film theory. The diffusion time $\left(t=d_{0}^{2} / D_{g}\right)$ is selected as time scale to predict the velocity of diffusion.

Table 1 Evaluation of the thermophysical properties

\begin{tabular}{|c|l|}
\hline Properties & \multicolumn{1}{|c|}{ Method } \\
\hline$\rho_{l}$ & Rackett $^{(10)}$ \\
\hline$k_{l}$ & Latini \& Pacetti $^{(10)}$ \\
\hline$\mu_{l}$ & Sastri-Rao method \\
\hline$c_{p, l}$ & Corresponding States Methods $(\mathrm{CSP})^{(10)}$ \\
\hline $\mathrm{L}$ & Watson relation $^{(10)}$ \\
\hline$c_{p, g}$ & Abramzon \& Sirignano $^{(13)},{\text { Wilke's } \text { method }^{(10)}}^{(10)}$ \\
\hline$\mu_{g}$ & Lucas $^{(10)}$, Lucas mixing rule $^{(10)}$ \\
\hline$k_{g}$ & Abramzon \& Sirignano $^{(13)},{\text { Wilke's } \text { method }^{(10)}}$ \\
\hline$D_{g}$ & Fuller et al. $^{(10)}$ \\
\hline
\end{tabular}


The present results obtained by this diffusion theory showed a good agreement with those using classical model as referred later.

The governing equations of gas and liquid phases are discretized into their algebraic counterparts based on the finite-volume method. Then, the SIMPLEC algorithm ${ }^{(14)}$ is applied to solve the gas and liquid flow fields, where the power-law scheme is used for the convective and diffusive flux of the control volume surface. The fully implicit scheme is utilized for time marching calculation.

In the present study, the computational domain is composed of several blocks. The grid locations inside the blocks containing droplets are changed, so are adjusted at each time step in order to keep a fine grid distribution near droplet surface when droplet surface is regressed. The non-uniform grid system has $25 \times 51$ points for the liquid-phase, and $59 \times 301$ points for the gas-phase. The body-fitted grid system is generated by the elliptic differential equation technique, where Poisson equations are solved to determine the values of curvilinear coordinates in physical plane ${ }^{(15)}$. Grid independence on variable grid size has been investigated through numerical experiments. The preliminary results indicate that the grid spacing variation makes a change less than $0.2 \%$ in droplet vaporization rate.

\section{Results and Discussion}

\subsection{Validation}

In the present study, internal circulating droplets of initial temperature $300 \mathrm{~K}$ are burning in a convective heated air stream of $10 \mathrm{~atm}$ and $1250 \mathrm{~K}$ under 5 to 50 Reynolds number range with regard to the fuel droplet. The convective time $\left(t=r_{0} / u_{g, \infty}\right)$ is selected as time scale to describe the transient behaviors of droplets. Also the fixed droplet distances of 5 radii to 40 radii horizontally and 3 radii to 24 radii vertically are selected.

Since experimental results for the burning of $n$ heptane droplet with internal circulation in a convective flow are not available at present, the present results for the diameter squared of $n$-heptane droplet are compared with those by Faeth ${ }^{(16),(17)}$. For droplet burning with forced convection, he recommends the following correlation in order to evaluate the burning rate, $\dot{m}_{f}$ :

$$
\dot{m}_{f}=\frac{2 \pi \bar{k}_{g} r_{s} N u}{\bar{c}_{p, q}} \ln \left(1+B_{o, q}\right)
$$

where

$$
\begin{aligned}
& N u=2+\frac{0.555 \operatorname{Re}^{1 / 2} \operatorname{Pr}^{1 / 3}}{\left[1+1.232 /\left(\operatorname{RePr}^{4 / 3}\right)\right]^{1 / 2}} \\
& B_{o, q}=\frac{\Delta h_{c} / v+\bar{c}_{p, g}\left(T_{\infty}-T_{s}\right)}{q_{l}+L}
\end{aligned}
$$

Also the burning rate, $\dot{m}_{f}$, to calculate the diameter variation can be expressed as

$$
\begin{aligned}
& \dot{m}_{f}=\frac{d}{d t}\left(\bar{\rho}_{l} V\right)=\bar{\rho}_{l} \frac{d V}{d t}+V \frac{d \bar{\rho}_{l}}{d t} \\
& \therefore \quad \frac{d r}{d t}=-\frac{1}{4 \bar{\rho}_{l} \pi r^{2}}\left(\int \dot{m}^{\prime \prime} d A+V \frac{d \bar{\rho}_{l}}{d t}\right)
\end{aligned}
$$

In these equations, the average transport properties are achieved by applying the ' $1 / 3$ rule', $R e$ is based on the droplet diameter and the relative velocity, and $\bar{\rho}_{l}$ is the spatial averaged density. Figure 2 shows that the time variations of the diameter squared are compared with those obtained from Eq. (13) for various Reynolds numbers, and shows that the present results give good predictions.

\subsection{Flame variations and liquid isotherms with Reynolds number}

In an oxidizing convective flow, depending on the Damköler number, $D a$, or the Reynolds number, various flame configurations such as wake flame, transition flame and envelope flame exist. The Damköler number represents the ratio of characteristic flow time to characteristic reaction time in the region of maximum reactivity. Since a large Damköler number means that the heat generated by combustion is more important than that lost from the flame to surrounding, the flame moves farther around the droplet forward, and an envelope flame retains. Figure 3 shows the present results of flame configuration with the Damköler number and the Reynolds number, and shows

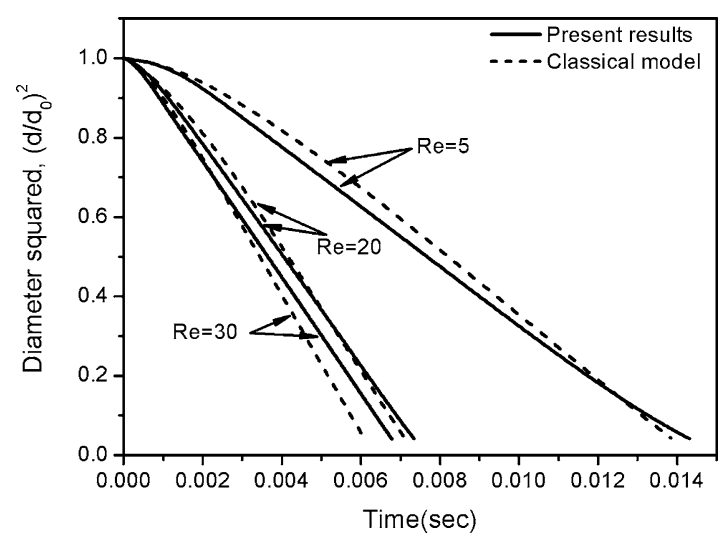

Fig. 2 Comparison with calculation by Faeth ${ }^{(16)}$ of $d^{2}$

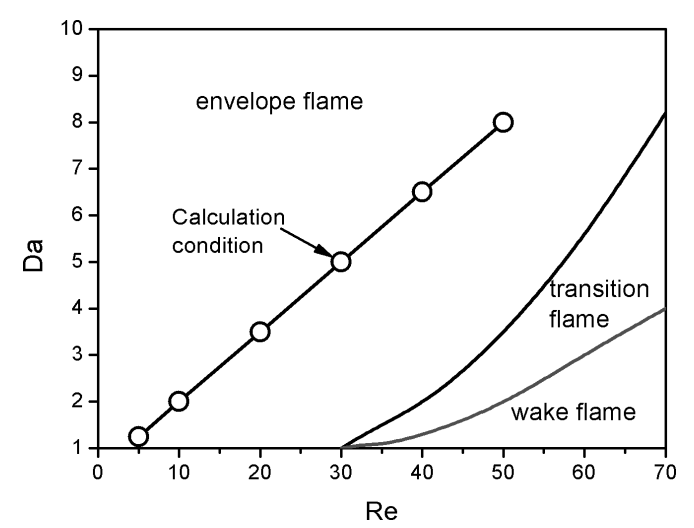

Fig. 3 Flame configuration for various $R e$ and $D a$, and calculation conditions with $R e$ 


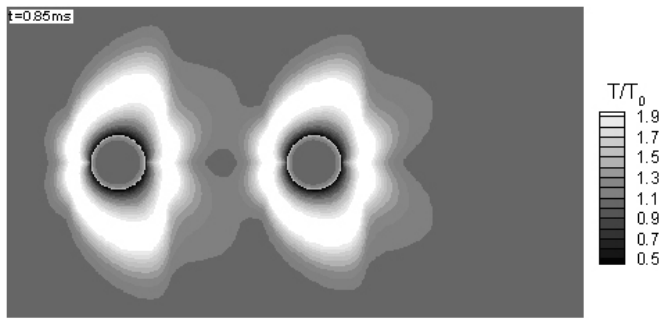

(a)

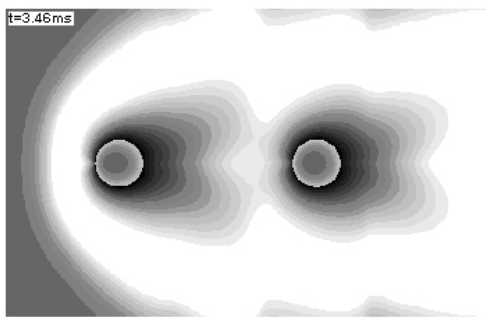

(b)

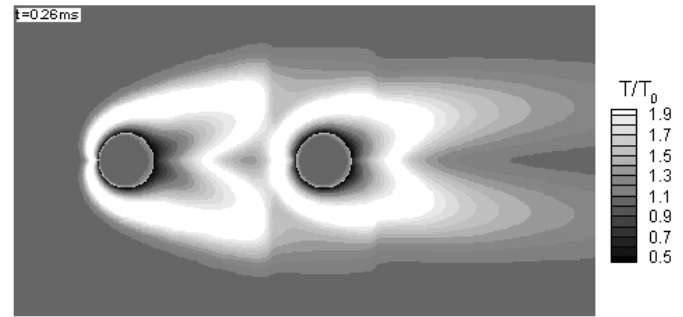

(c)

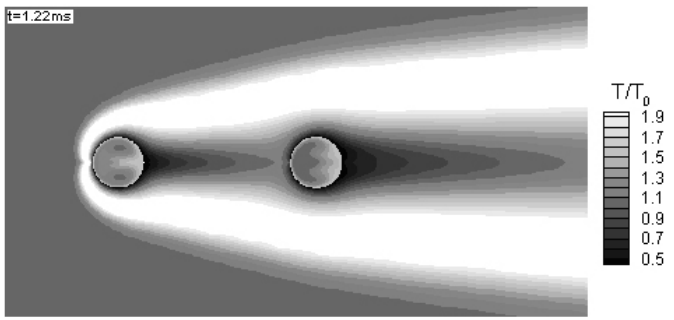

(d)

Fig. 4 Flame configuration and liquid phase isotherms with time at $D=7$ and $H=24$ : (a)(b) $R e=10$, (c)(d) $R e=50$

the consistence with previous results ${ }^{(8),(9)}$. In the present study, burning droplets with envelope flame are considered for the simplification, also calculation conditions of the present study are presented in Fig. 3.

Figure 4 shows flame configuration and liquid isotherms at $R e=10$ and 50 when the horizontal droplet spacing which is nondimensionalized by $r_{0}, D$, is 7 and the non-dimensional vertical droplet spacing, $H$, is 24 . It also shows that the droplets injected into hot air start with individual flames surrounding each droplet, and then form single flame. As the oxidizer between two droplets is consumed by the scavenging combustion, the flames grow until they merge with each other into a single flame that surrounds the droplets, as shown in Fig. 4(b) and (d). After the scavenging combustion, environmental temperature of the second droplet is relatively lower. At a low Reynolds number of 10, the leading flame's characteristic length is thicker and wider, whereas the flame thickness is thinner at a high Reynolds number of 50. Streamlines inside the droplet in this case are similar to Hill's vortex. The isotherm pattern of liquid phase, however, is not similar to streamline distribution because of weak convective effect. Therefore, heat transfer to droplet interior is believed to be conduction-dominated. Liquid phase isotherms of two droplets are similar, as shown in Fig. 4 (b), because of weak convective effect.

Figure 5 shows the detailed droplet heating history including the streamlines and isotherms for two droplets at the same conditions when Reynolds number is 50 .

Initially, the heat transfer mechanism inside the droplet is dominated by diffusion at both $R e=10$ and $R e=50$. At a high Reynolds number of 50, isotherms and streamlines inside the first droplet are very similar.
The mixing of the high temperature region near the surface with lower temperature region inside droplet occurs rapidly because of strong convective effect of internal flow fields, therefore the heat transfer to droplet interior is convection-dominated. However, liquid phase isotherms of the first and second droplets are not similar, as shown in Fig. 5, because the mixing mode for the second droplet is retarded due to weak convective effect of the second droplet.

\subsection{Horizontal droplet spacing effects}

Figure 6 shows flame configuration and liquid isotherms at $R e=10$ for the cases of $D=5$ and 9 . As the horizontal droplet spacing decreases, the scavenging combustion and single flame mode occur rapidly. The vaporization rate of fuel droplets is strongly affected by the flame configuration surrounding droplets. At a lower Reynolds number, the fuel vapor transferred mainly from the first droplet with decreasing horizontal droplet spacing is accumulated between two droplets. For the first droplet, fuel vapor accumulation with decreasing horizontal droplet spacing retards the ascent of droplet surface temperature at the rear of droplet because the temperature of fuel vapor is lower. For the second droplet, the single flame mode through the scavenging combustion with decreasing horizontal droplet spacing also prevents the surface temperature at the rear of droplet from rising. These fuel vapor accumulation effect and the single flame mode through the scavenging combustion reduce the vaporization rate of the first droplet by about $5 \%$, and the second droplet by about $40 \%$.

The ratio of mass burning rate of two droplets to that of single droplet for various Reynolds numbers is presented in Fig. 7, in which the ratio is calculated when 

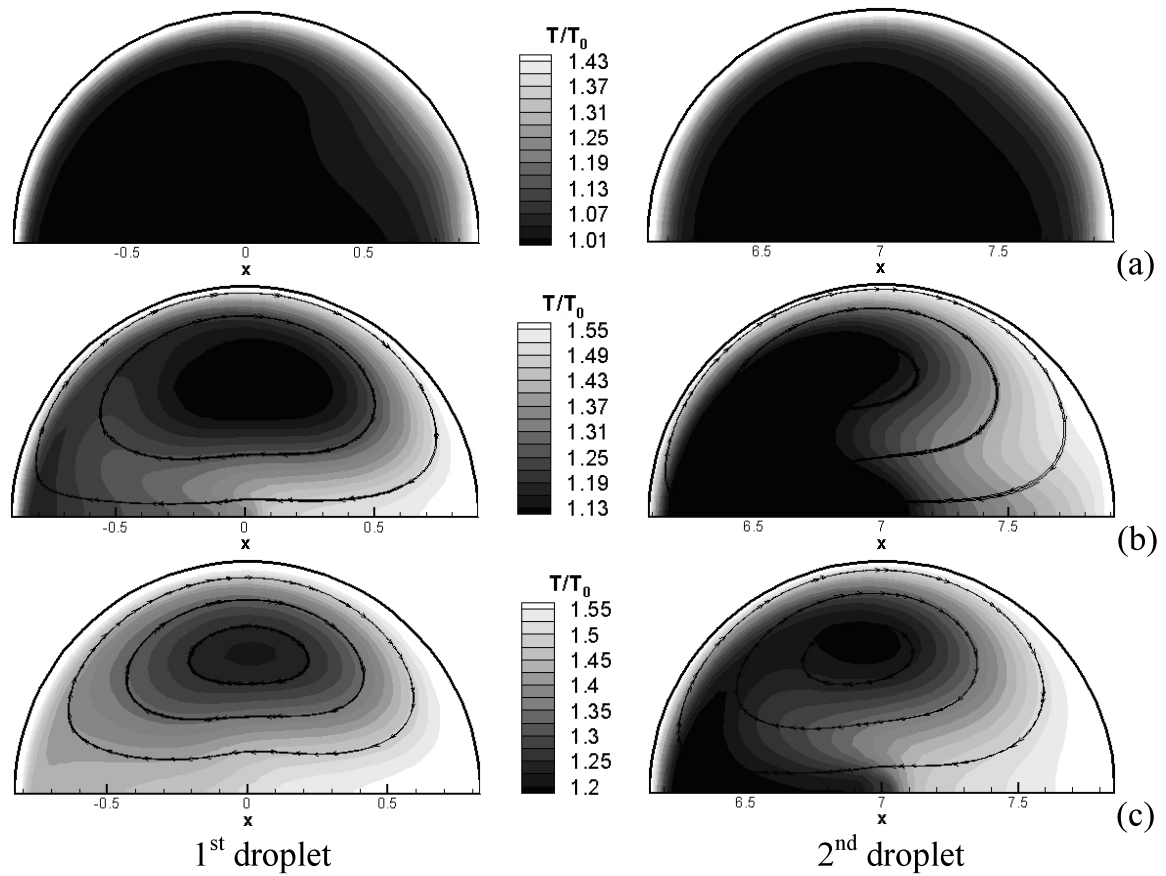

Fig. 5 Time history of streamlines and isotherms for two droplets at $D=7, H=24$ and $R e=50$ : (a) $0.26 \mathrm{~ms}$ (b) $1.22 \mathrm{~ms}$ and (c) $2.04 \mathrm{~ms}$
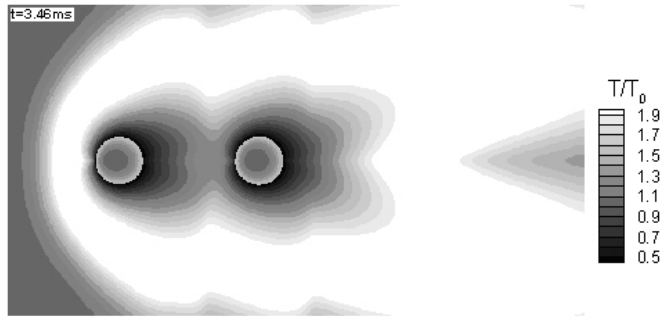

(a)
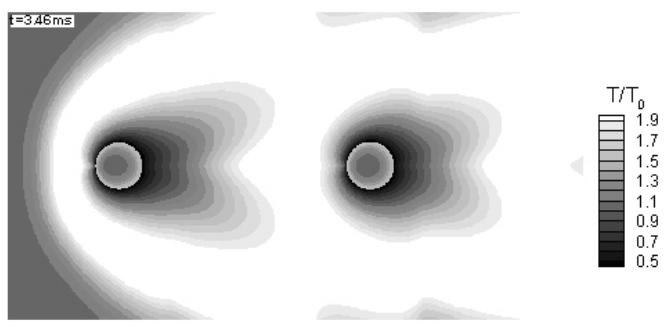

(b)

Fig. 6 Flame configuration and liquid phase isotherms with the horizontal droplet spacing at $H=24$ for $R e=10$ : (a) $D=5$, (b) $D=9$

the initial droplet mass is reduced to $90 \%$ for the first droplet, and to $85 \%$ for the second droplet. At a higher Reynolds number (>10), the retardation effect for the first droplet with decreasing horizontal droplet spacing reduces because fuel vapor accumulation is less serious in the inter-droplet region with a stronger convective flow in Fig. 7 (a). For the second droplet, at a higher Reynolds number ( $>10$ ), the mixing mode of liquid phase through the single flame mode occurs slowly because of a weaker

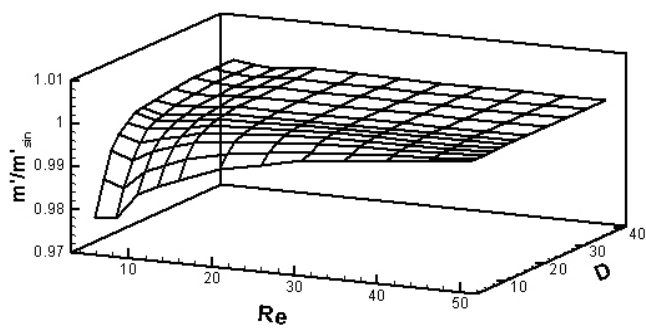

(a)

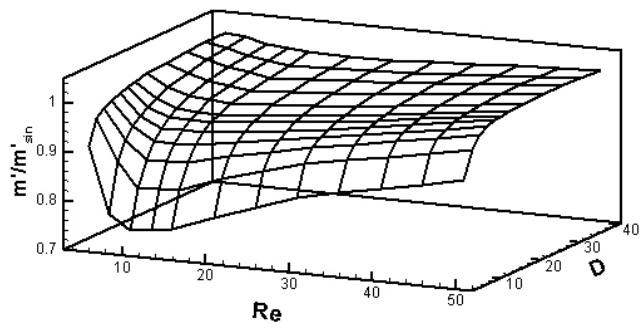

(b)

Fig. 7 Ratio of burning rate of two droplets to that of single droplet for various horizontal droplet spacing and $R e$ at $H=24$ : (a) 1st droplet, (b) 2nd droplet

convective flow. Through the single flame mode and accumulation effect, as the heat flux from the flame to the second droplet is smaller, the mixing with the low temperature region inside droplet acts as a heat sink. Therefore, the ratio of burning rate with decreasing horizontal droplet spacing and decreasing Reynolds number exhibits remarkable decrease in Fig. 7 (b). At a lower Reynolds number $(<10)$, however, these single flame effect and retardation effect of liquid phase are reduced. The reason is that un- 


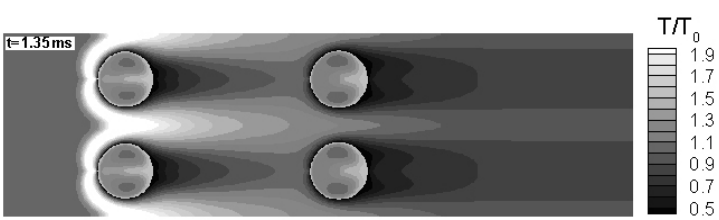

(a)

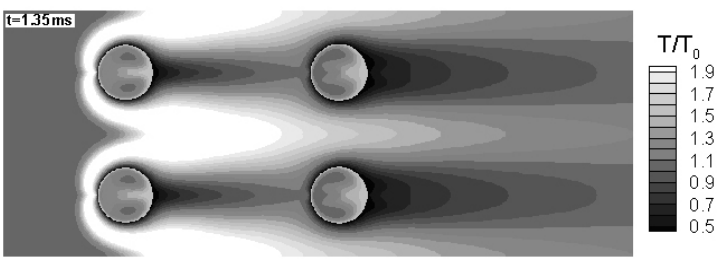

(b)

Fig. 8 Flame configuration and liquid phase isotherms with the vertical droplet spacing at $D=7$ for $R e=30$ : (a) $H=3$, (b) $H=4$

der weak convective flow, the single flame mode which reduces burning rate occurs slowly and the interaction of the second droplet with gas phase decreases.

\subsection{Vertical droplet spacing effects}

As the flow accelerates with the decreasing vertical droplet spacing, the surface velocities of two droplets and heat transferred to adjacent droplets increase. These flow acceleration effects are maintained until the vertical droplet spacing, $H$, is 5 . If $H$ is smaller than 5, heat transferred to both droplets decreases because of the reduction of flame penetration depth.

Figure 8 shows the flame configurations of droplets for the different vertical droplet spacing at $R e=30$. As the vertical droplet spacing decreases, the flame is not propagated to the first droplet backward due to the oxygen starvation after the scavenging combustion and forms the incomplete envelope flame. Also, as Reynolds number decrease, the flame penetration depth is observed to decrease.

These flame shapes under the present conditions are classified into external or internal group combustion in previous study of Chiu et al. ${ }^{(1)}$, whose study was reinforced by the experimental results by Nagata et al. ${ }^{(4)}$ The present results that the flame penetration depth with decreasing mean droplet spacing decreases, and that the burning rate of the second droplet decreases because of the reduction of flame penetration depth, demonstrate a good agreement with previous studies.

Figure 9 shows the ratio of burning rate of interacting droplets to that of single droplet at $D=15$, in which the second droplet is under weak interaction with the first droplet. At a lower Reynolds number, the flow acceleration with decreasing vertical droplet spacing enhances the burning rate of two droplets. If the vertical droplet spacing is smaller than $5 r_{0}$, however, effects of flow acceleration are reduced because the reduction of the flame penetration

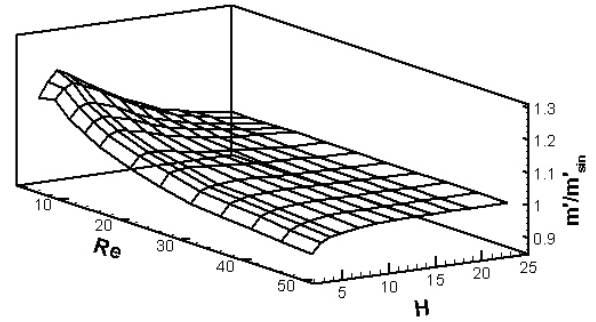

(a)

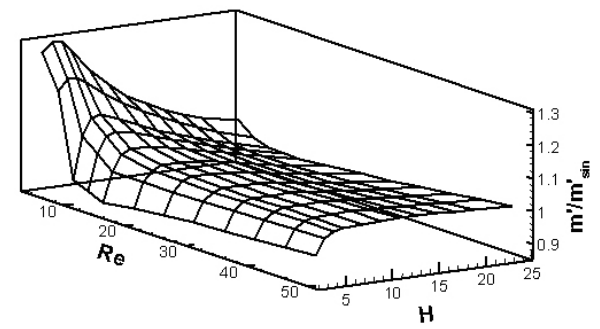

(b)

Fig. 9 Ratio of burning rate of two droplets to that of single droplet for various vertical droplet spacing and $R e$ at $D=15$ : (a) 1st droplet, (b) 2nd droplet

depth with decreasing vertical droplet spacing does not enhance the heat transfer to the second droplet any more. At a higher Reynolds number ( $>30$ ), for the first droplet, the flow acceleration with decreasing vertical droplet spacing dose not enhance the heat transfer of droplet inside any more because the internal convective flow is very strong. The reduction of flame penetration depth with decreasing vertical droplet spacing gradually reduces the burning rate of the first droplet.

A series of calculations have been conducted to investigate the ratio of burning rate of interacting droplets with combustion to that of single droplet burning which used both the present results and the classical model, as a function of Reynolds number, horizontal droplet spacing and vertical droplet spacing. The burning rate of interacting droplets can be described by the following equation.

$$
\left(\dot{m}_{1} \text { or } \dot{m}_{2}\right) / \dot{m}_{\text {sin }}=C_{1}(R e)^{C_{2}} D^{C_{3}} H^{C_{4}}
$$

The coefficients are presented in Table 2 , and are determined using the results for $5 \leq R e \leq 50,5 \leq D \leq 40$ and $3 \leq H \leq 24$. This correlation provides a convenient means to estimate the burning rate of interacting droplet by means of that of single droplet.

\section{Conclusion}

A comprehensive analysis for the vaporization and combustion of interacting droplets with internal circulation was predicted numerically with the effects of Reynolds numbers, horizontal droplet spacing, and vertical droplet spacing. Results indicate that the droplet spacing significantly influences the droplet burning behavior. For the first droplet, the burning rate with decreasing vertical droplet spacing is enhanced compared to that of single 
Table 2 Coefficients of correlation

\begin{tabular}{|c|c|c|c|c|c|c|}
\hline Base & Droplet & $\mathrm{C}_{1}$ & $\mathrm{C}_{2}$ & $\mathrm{C}_{3}$ & $\mathrm{C}_{4}$ & Range of H \\
\hline \multirow{3}{*}{$\begin{array}{c}\text { Present } \\
\text { results }\end{array}$} & \multirow{2}{*}{$1^{\text {st }}$ droplet } & 1.2235 & -0.0970 & 0.0884 & 0.0003 & $3 \leq H \leq 5$ \\
\cline { 2 - 7 } & \multirow{2}{*}{$2^{\text {nd }}$ droplet } & 1.2522 & -0.0277 & -0.0495 & 0.0035 & $5<H \leq 24$ \\
\cline { 3 - 7 } & 1.0864 & -0.0186 & -0.0904 & 0.0767 & $5<H \leq 24$ \\
\hline \multirow{3}{*}{$\begin{array}{c}\text { Classical } \\
\text { model }\end{array}$} & \multirow{2}{*}{$1^{\text {st }}$ droplet } & 1.5310 & -0.1831 & 0.0843 & -0.0001 & $3 \leq H \leq 5$ \\
\cline { 2 - 7 } & \multirow{2}{*}{$2^{\text {nd }}$ droplet } & 1.6624 & -0.1295 & -0.0603 & 0.0053 & $5<H \leq 24$ \\
\cline { 3 - 7 } & 1.0561 & -0.2021 & 0.1686 & 0.1058 & $3 \leq H \leq 5$ \\
\hline
\end{tabular}

droplet because of flow acceleration. However, it is reduced with decreasing horizontal droplet spacing because of fuel accumulation between droplets.

As the Reynolds number increases, effects of the horizontal droplet spacing on the burning rate decrease. For the second droplet, during the scavenging combustion the burning rate is similar to the trend of the first droplet. After the scavenging combustion, however, the burning rate with decreasing horizontal droplet spacing or with decreasing vertical droplet spacing is remarkably reduced to that of single droplet because of the single flame effects and the reduction of flame penetration depth. The calculated burning rate varies exponentially with the droplet spacing, and can be correlated satisfactorily to that of single droplet burning in terms of the Reynolds number, the horizontal droplet spacing and the vertical droplet spacing.

\section{Acknowledgements}

The authors wish to express their thanks for the support of Combustion Engineering Research Center (CERC) of Korea.

\section{References}

( 1 ) Chiu, H.H., Kim, H.Y. and Croke, E.J., Internal Group Combustion of Liquid Droplets, 19th Symp. (Int.) on Combustion, (1982), pp.971-980.

( 2 ) Xiong, T.Y., Law, C.K. and Miyasaka, K., Interactive Vaporization and Combustion of Binary Droplet Systems, 20th Symp. (Int.) on Combustion, (1985), pp.1781-1787.

( 3 ) Okai, K., Ono, Y., Moriue, O., Shiba, S., Araki, M., Nomura, H., Shiga, S., Tsue, M. and Kono, M., Interaction Effects on Combustion of Alcohol Droplet Pairs, JSME Int. J., Ser. B, Vol.44, No.1 (2001), pp.126-132.

( 4 ) Nagata, H., Kudo, I., Ito, K., Nakamura, S. and Takeshita, Y., Interactive Combustion of TwoDimensionally Arranged Quasi-Droplet Clusters under Microgravity, Combust. Flame, Vol.129 (2002), pp.392-400.

( 5 ) Umemura, A., Ogawa, S. and Shima, N., Analysis of the Interaction between Two Burning Droplets, Combust. Flame, Vol.41 (1981), pp.45-55.

( 6 ) Umemura, A., A Unified Theory of Quasi-Steady Droplet Combustion, 18th Symp. (Int.) on Combustion, (1981), pp.1355-1363.

( 7 ) Prakash, S. and Sirignano, W.A., Theory of Convective Droplet Vaporization with Unsteady Heat Transfer in the Circulating Liquid Phase, Int. J. Heat Mass Transfer, Vol.23 (1980), pp.253-268.

( 8 ) Dwyer, H.A. and Sanders, B.R., Calculations of Unsteady Reacting Droplet Flows, 22nd Symp. (Int.) on Combust., (1988), pp.1923-1929.

( 9 ) Jiang, T.L., Chen, W.S., Tsai, M.J. and Chiu, H.H., A Numerical Investigation of Multiple Flame Configurations in Convective Droplet Gasification, Combust. Flame, Vol.103 (1995), pp.221-238.

(10) Poling, B.E., Prausnitz, J.M. and O'Connell, J.P., The Properties of Gases and Liquids, (2001), McGraw-Hill, New York.

(11) Westbrook, C.K. and Dryer, F.L., Simplified Reaction Mechanisms for the Oxidation of Hydrocarbon Fuels in Flames, Combust. Sci. and Tech., Vol.27 (1981), pp.31-43.

(12) Cussler, E.L., Diffusion Mass Transfer in Fluid Systems, (2002), Chapter 3, Cambridge.

(13) Abramzon, B. and Sirignano, W.A., Droplet Vaporization Model for Spray Combustion Calculations, Int. J. Heat. Mass Transfer, Vol.32, No.9 (1989), pp.16051618.

(14) van Doormal, J.P. and Raithby, G.D., Enhancement of the SIMPLE Method for Predicting Incompressible Fluids Flows, Numerical Heat Transfer, Vol.7 (1984), pp.147-163.

(15) Thompson, J.F., Warsi, Z.U.A. and Mastin, C.W., Numerical Grid Generation: Foundations and Applications, (1985), North-Holland, NewYork.

(16) Faeth, G.M., Current Status of Droplet and Liquid Combustion, Prog. in Energy and Combust. Sci., Vol.3 (1977), pp.191-244.

(17) Turns, S.R., An Introduction to Combustion, (2000), Chapter 10, McGraw-Hill, New York. 